\title{
Achieving Sustainability through Innovation-led Lean Approaches to Manufacturing Supply Chains
}

\author{
Arijit Bhattacharya ${ }^{1}$, Prasanta Kumar Dey ${ }^{2}$ \\ ${ }^{1}$ Norwich Business School, University of East Anglia \\ Norwich Research Park, Norwich, NR4 7TJ, United Kingdom. \\ Telephone: +44-(0)-1603 597520 \\ e-mail: A.Bhattacharya@uea.ac.uk; arijit.bhattacharya2005@gmail.com \\ ${ }^{2}$ Aston Business School, Aston University \\ Aston Triangle, Birmingham, B4 7ET, United Kingdom. \\ Telephone: +44-(0)-121 2044011 \\ e-mail: p.k.dey@aston.ac.uk
}

\section{Introduction}

A critical examination of real-world manufacturing supply chain operations proves that innovation helps in achieving sustainability through waste reduction. Prior studies reveal that firms' innovative capabilities focusing on waste reduction have a positive impact on environmental sustainability, energy efficiency, supply chain integration, risk management, responsiveness and enhanced supply chain performance (Hernandez-Vivanco et al., 2018; Dey et al., 2019a). Recent advances in manufacturing technology, information and communication technology (e.g. Industry 4.0 and block chain, etc.) and process innovations (e.g. lean, six sigma and sustainability oriented innovation) facilitate manufacturing supply chains to achieve sustainable business performance.

Lean approaches help in achieving environment-friendly practices in business (Duarte and Cruz-Machado, 2013; Ball, 2015; Hofer et al., 2012; Wee and Wu, 2009; McIvor, 2001). Process innovation facilitates the adoption of both lean and green approaches, leading to synergy between them (Dey et al., 2019b). As a lean approach is efficiency focused, and sustainability is the most appropriate trade-off among economic, environmental and social practices (Piercy and Rich, 2015; Ogunbiyi et al., 2014; Miller et al., 2010), achieving sustainable business performance requires process innovation, which is different from traditional innovation. One paradigm of current research into sustainability is to achieve green through a lean approach (Dües et al., 2013; King and Lenox, 2001), which may be appropriate for sub-optimal businesses. However, research has shown that businesses must sacrifice efficiency to achieve superior environmental and social performance.

Another research paradigm suggests that organisations need to consider supply chain sustainability, rather than look at the problem only from individual stakeholder perspectives. 
Supply chain sustainability can be achieved through a trade-off between the efficiency and responsiveness dimensions across the supply chain drivers (e.g., facilities, transportation, inventory, information, sourcing and pricing), through consideration of environmental and social criteria, along with customer requirements, when making decisions at strategic, planning and operational levels.

Although supply chain sustainability, the lean approach and process innovation (Williamson et al., 2004; Tan et al., 2015; Lii and Kuo, 2016; Jabbour et al., 2015) have been separately researched extensively in the recent past, as has the contribution of process innovation to achieving lean and green independently, there is a knowledge gap in combinative approaches of supply chain sustainability, lean methods and process innovation, which gives rise to undertake research innovation-led lean approaches and its implications on manufacturing supply chain performance.

This special issue entitled 'Achieving Sustainability through Innovation-led Lean Approaches to Manufacturing Supply Chains' aims to collate recent research on achieving supply chain sustainability through innovation across manufacturing processes with the adoption of lean approach using both empirical and theoretical frameworks. The selected articles in this special issue identify the growing consensus that firms should manage in reducing waste through innovative capabilities in order to achieve sustainable outcomes. The articles reveal new knowledge in the area of sustainability oriented innovation to researchers and industry practitioners that facilitates identify newer research questions for the researchers and advance practices for the industry people. The published articles in this special issue address at least one of the following research questions (Bhattacharya and Dey, 2016):

a) How does process innovation leading towards lean process thinking help bring sustainability to manufacturing supply chain operations?

b) What effect does implementation of innovation-based lean approaches in manufacturing supply chains have on key supply chain constructs and sustainability?

c) How can sustainability become the third dimension of the manufacturing supply chain, along with the efficiency and responsiveness dimensions, by converging process innovation and lean process linking to a common deliverable, sustainability, in order to achieve business goals?

There was an encouraging response to the call for papers for this special issue with 60 submissions. A rigorous review process was followed to identify top eight high-quality research contributions presenting new and significant research in the relevant areas. Contributions mainly present new approaches in reducing waste through innovation-led lean approaches to achieve sustainable outcomes applied to manufacturing supply chains.

\section{An Outline of the Special Issue Articles}

The following paragraphs elucidate the contributions of eight selected articles of this special issue covering significance, problem statements, methodology, findings and contributions. 
Deployment of appropriate new practices and technologies can offer innovation-led lean activities resulting in simultaneous enhancement of eco-efficiency in manufacturing. Ball and Lunt (2019) in their article entitled "Lean eco-efficient innovation in operations through the maintenance organisation" report a case-based research to elucidate how maintenance supports eco-efficiency practice through innovation in lean operations. The research highlights the role of community, training, tools and organisational structure in ensuring that eco-efficiency targets are pursued. This article considers the role of community, training, tools and organisational structure to ensure the eco-efficiency targets using the case of a large European aerospace manufacturer.

De et al. (2019) in their article titled "Impact of lean and sustainability oriented innovation on sustainability performance of small and medium sized enterprises: A data envelopment analysis-based framework" study the combined effect of lean practices and sustainability oriented innovation (SOI) on supply chain sustainability performance of Indian SMEs using a Data Envelopment Analysis (DEA) framework. The outcomes of this research report that combined lean and SOI facilitate to achieve SMEs' supply chain sustainability performance.

Process innovation leading towards increased operational efficiency can have direct impact on increased efficient, lean and sustainable operations. The article entitled "Strategic incentives for complementary producers to innovate for efficiency and support sustainability" by Dobson and Chakraborty (2019) studies the impact of providing remuneration incentives to the managers supported by public commitments to increase innovation effort for efficient, lean and sustainable operations. The outcomes of the article demonstrate the necessity of governmentbacked voluntary agreements to encourage investment in process innovation that supports lean approaches and sustainability in supply chains.

Genc and De Giovanni (2019) in their article titled "Closed-loop supply chain games with innovation-led lean programs and sustainability" examines the impact of innovation-led lean programs within a Closed-loop Supply Chain (CLSC) using a game-theoretic approach. The research findings indicate that the lean practices leading to both strategic and process innovation give rise to sustainability and have favourable impacts on the manufacturing.

Additive manufacturing (AM) or three-dimensional (3D) has capability to eliminate / remove the waste and simultaneously achieve sustainability. The article entitled "Examining legitimatisation of additive manufacturing in the interplay between innovation, lean manufacturing and sustainability" by Ghobadian et al. (2019) examines AM's capability of significantly reducing/eliminating waste to achieve sustainability. The article concludes that legitimation of AM can ensure its deep and broad diffusion to achieve lean manufacturing, i.e. waste reduction, and sustainability.

The article of Kumar and Rodrigues (2019) titled "Synergetic effect of lean and green on innovation: A resource-based perspective" examines, using a theoretical lens of resource-based view, the ways to adapt the synergetic relationship between lean and green (i.e. sustainable) practices through fostering innovative practices. The research adopts an exploratory case study 
methodology in two manufacturing organisations in the UK. The research evidences role of innovation in fostering synergetic relationship between lean and green practice implementation.

It is important to examine the dynamic behaviour of the key drivers of innovation-led lean approaches and their influence on sustainable performance in manufacturing supply chains. Orji and Liu (2019), in their article titled "A dynamic perspective on the key drivers of innovation-led lean approaches to achieve sustainability in manufacturing supply chain", prioritises the key drivers of innovation-led lean approaches to achieve sustainability in the manufacturing supply chains. A fuzzy set based Technique for Order Performance by Similarity to Ideal Solution (Fuzzy TOPSIS) method is applied. Further, a system dynamics model investigates the dynamic behaviour of the key drivers and their influence on sustainable performance over a long time.

Rathore et al. (2019), in their article entitled "Examining the mediating role of innovative capabilities in the interplay between lean processes and sustainable performance", hypothesise and establish that innovative capabilities of a lean firm mediate the relationship between the firm's lean approaches and its sustainable performance. In this article an iterative and recursive two-phase framework proposes that lean processes can positively or negatively impact a firm's sustainable performance based on its state of innovative capabilities. The framework is inspired by a metaheuristic analogy, which discusses switching behaviour at the decoupling point in a lean firm's innovation strategy. Primary and secondary data for automobile industry are used in the proposed framework to triangulate the results.

\section{Future Research Direction}

The authors of the special issue articles underline further scope of research in the emerging area of combinative capabilities of the innovation-led lean approaches and sustainability. Ball and Lunt (2019) suggest to examine the implementations of lean eco-efficient innovation within smaller companies across the industries. They also propose to explore if manufacturers that lead their eco-efficiency through their maintenance function perform better through greater innovation than those who use other organisational arrangements. The third recommendation for future studies is to contrast the types of innovation, i.e. incremental and radical, that maintenance drives with other organisational functions. De et al. (2019) suggest to study the impact of lean and sustainability oriented innovation (SOI) on sustainability performance considering different regions, and economies along with exploring the impact of the policy, funding and legislation on lean and SOI and its impact on supply chain sustainability along with the impact of the CSR, lean and SOI on the supply chain sustainability of SMEs. Dobson and Chakraborty (2019) propose to explore stochastic innovation, which provides a stronger need for collaboration on innovation effort, to allow variable proportions rather than fixed proportions technology in the assembly industry, and to consider innovation incentives across overlapping or competing supply chains. Genc and De Giovanni (2019) suggest to extend their proposed model by including multi-period strategic interactions facilitating a better understanding of long-term environmental impact of the innovation-led lean programmes, to examine competition in innovation-led lean programs, to extend the model allowing splitting 
the costs of lean operations in upstream and downstream operations, and to include other forms of non-strategic and strategic lean activities into an extended version of the model.

Ghobadian et al. (2019) propose to conduct an empirical research to examine how additive manufacturing can contribute to the economic and social aspects of sustainability and how its adoption can represent the frontier of lean manufacturing capabilities. Kumar and Rodrigues (2019) recommend a large-scale questionnaire-instrument to survey a larger sample of operations from a wider range of sectors and countries to test the two proposed hypotheses, additionally to conduct an action research to have greater understanding of the impact of specific innovation, and the influence of the success factors and barriers affecting green-lean projects, considering a wide range of stakeholders. Orji and Liu (2019) suggest a longitudinal assessment of the key drivers of innovation-led lean approaches to achieve supply chain sustainability within a single manufacturing industry (e.g. metal products industry) along with comparative analysis with other industries. Rathore et al. (2019) recommend the use of more extensive pan industry database to examine the applicability of the proposed framework in firms pertaining to different industries.

In addition to the afore-stated research opportunities identified by the authors of this special issue, future research could focus on exploring the causal relationship among the constructs derived from waste reduction through innovation-led lean approaches to achieve sustainable manufacturing supply chain operations and its superior performance that facilitates industry practitioners and policymakers in achieving greater sustainability practices.

\section{Acknowledgement}

The editors of this special issues take the opportunity to acknowledge the efforts of all the contributing authors, convey heartfelt thanks to all the reviewers for spending their valuable time in reviewing the manuscripts and providing useful and constructive comments, which made this special issue possible. The guest editors would like to thank Professor Stefan Minner, the Editor-in-Chief, and Professor T.C. Edwin Cheng, the Asian-Pacific Editor of the International Journal of Production Economics, for their immense cooperation and constructive advice. Further, the guest editors acknowledge the continuous support provided by the colleagues of editorial office. The guest editors believe that this special issue will contribute significantly in the areas of waste reduction through innovation-led lean approaches that result in sustainable manufacturing supply chain operations.

\section{References}

Ball, P., Lunt, P., 2019. Lean eco-efficient innovation in operations through the maintenance organisation. International Journal of Production Economics, DOI: https://doi.org/10.1016/j.ijpe.2018.07.007.

Ball, P., 2015. Low energy production impact on lean flow. Journal of Manufacturing Technology Management, 26(3), 412-428. 
Bhattacharya, A., Dey, P.K., 2016. Call for paper on "Achieving Sustainability through Innovation-led Lean Approaches to Manufacturing Supply Chains”. International Journal of Production Economics.

De, D., Chowdhury, S., Dey, P.K., Ghosh, S.K., 2019. Impact of lean and sustainability oriented innovation on sustainability performance of small and medium sized enterprises: A data envelopment analysis-based framework. International Journal of Production Economics, DOI: https://doi.org/10.1016/j.ijpe.2018.07.003.

Dey, P. K.; Malesios, C., De, D., Chowdhury, S., Abdelaziz, F. B., 2019a, Could lean practices and process innovation enhance supply chain sustainability of small and medium-sized enterprises? Business Strategy and Environment, DOI: https://doi.org/10.1002/bse.2266.

Dey, P. K., Malesios, C., Abdelaziz, F. B, Chowdhury, S., De, D., 2019b, The impact of lean management practices and sustainable oriented innovation on sustainability performance of small and medium sized enterprises: Empirical evidence from the UK. British Journal Management, in press.

Dobson, P.W., Chakraborty, R., 2019. Strategic incentives for complementary producers to innovate for efficiency and support sustainability. International Journal of Production Economics, DOI: https://doi.org/10.1016/j.ijpe.2018.02.001.

Duarte, S., Cruz-Machado, V., 2013. Lean and green supply chain initiatives: A case study. In: Proceedings of the 2013 Industrial and Systems Engineering Research Conference, pp. 2168-2177.

Dües, C.M., Tan, K.H., Lim, M., 2013. Green as the new lean: how to use lean practices as a catalyst to greening your supply chain. Journal of Cleaner Production, 40, 93-100.

Genc, T.S., De Giovanni, P., 2019. Closed-loop supply chain games with innovation-led lean programs and sustainability. International Journal of Production Economics, DOI: https://doi.org/10.1016/j.ijpe.2018.05.026.

Ghobadian, A., Talavera, I., Bhattacharya, A., Kumar, V., Garza-Reyese, J.A., O'Regan, N., 2019. Examining legitimatisation of additive manufacturing in the interplay between innovation, lean manufacturing and sustainability. International Journal of Production Economics, DOI: https://doi.org/10.1016/j.ijpe.2018.06.001.

Hernandez-Vivanco, A., Bernardo, M., Cruz-Cázaresa, C., 2018. Sustainable innovation through management systems integration. Journal of Cleaner Production, 196, 1176-1187.

Hofer, C., Eroglu, C., Hofer, A.R., 2012. The effect of lean production on financial performance: The mediating role of inventory leanness. International Journal of Production Economics, 138(2), 242-253. 
Jabbour, C.J.C., Neto, A.S., Gobbo Jr., J.A., Ribeiro, M.S., Jabbour, A.B.L.S., 2015. Ecoinnovations in more sustainable supply chains for a low-carbon economy: A multiple case study of human critical success factors in Brazilian leading companies. International Journal of Production Economics, 164, 245-257.

King, A.A., Lenox, M.J., 2001. Lean and green? An empirical examination of the relationship between lean production and environmental performance. Production and Operations Management, 10(3), 244-256.

Kumar, M., Rodrigues, V.S., 2019. Synergetic effect of lean and green on innovation: A resource-based perspective. International Journal of Production Economics, DOI: https://doi.org/10.1016/j.ijpe.2018.04.007.

Lii, P., Kuo, F.-I., 2016. Innovation-oriented supply chain integration for combined competitiveness and firm performance. International Journal of Production Economics, $174,142-155$.

McIvor, R., 2001. Lean supply: the design and cost reduction dimensions. European Journal of Purchasing \& Supply Management, 7(4), 227-242.

Miller, G., Pawloski, J., Standridge, C., 2010. A case study of lean, sustainable manufacturing. Journal of Industrial Engineering and Management, 3(1), 11-32.

Ogunbiyi, O., Oladapo, A., Goulding, J., 2014. An empirical study of the impact of lean construction techniques on sustainable construction in the UK. Construction Innovation, 14(1), 88-107.

Orji, I.J., Liu, S., 2019. A dynamic perspective on the key drivers of innovation-led lean approaches to achieve sustainability in manufacturing supply chain. International Journal of Production Economics, DOI: https://doi.org/10.1016/j.ijpe.2018.12.002.

Piercy, N., Rich, N., 2015. The relationship between lean operations and sustainable operations. International Journal of Operations \& Production Management, 35(2), 282-315.

Rathore, H., Jakhar, S.K., Bhattacharya, A., Madhumitha, E. 2019. Examining the mediating role of innovative capabilities in the interplay between lean processes and sustainable performance. International Journal of Production Economics, DOI: https://doi.org/10.1016/j.ijpe.2018.04.029.

Tan, K.H., Zhan, Y.Z., Ji, G., Ye, F., Chang, C., 2015. Harvesting big data to enhance supply chain innovation capabilities: An analytic infrastructure based on deduction graph. International Journal of Production Economics, 165, 223-233. 
Wee, H.M., Wu, S., 2009. Lean supply chain and its effect on product cost and quality: A case study on Ford Motor Company, Supply Chain Management: An International Journal, 14(5), 335-341.

Williamson, E.A., Harrison, D.K., Jordan, M., 2004. Information systems development within supply chain management. International Journal of Information Management, 24(5), 375385. 